\title{
Correction to: Trial of healthy relationship initiatives for the very early years (THRIVE), evaluating Enhanced Triple P for Baby and Mellow Bumps for those with additional social and care needs during pregnancy and their infants who are at higher risk of maltreatment: study protocol for a randomised controlled trial
}

\author{
Marion Henderson ${ }^{1 *}$, Anja Wittkowski ${ }^{2}$, Emma Mclntosh $^{3}$, Alex McConnachie ${ }^{4}$, Katie Buston ${ }^{1}$, Philip Wilson $^{5}$, \\ Rachel Calam², Helen Minnis ${ }^{6}$, Lucy Thompson ${ }^{5,6}$, John O'Dowd ${ }^{7}$, James Law ${ }^{8}$, Elizabeth McGee ${ }^{9}$, \\ Daniel Wight ${ }^{1}$ and THRIVE Trial Research Team
}

Correction to: Trials (2019) 20:499

https://doi.org/10.1186/s13063-019-3571-5

Following publication of the original article [1], it has been brought to our attention that an error was slipped into the article's title.

- Initially published title:

Trial of healthy relationship initiatives for the very early years (THRIVE), evaluating Enhanced Triple P for Baby and Mellow Bumps additional social and care needs during pregnancy and their infants who are at higher risk of maltreatment: study protocol for a randomised controlled trial

- Corrected title:

Trial of healthy relationship initiatives for the very early years (THRIVE), evaluating Enhanced Triple P for Baby and Mellow Bumps for those with additional social and care needs during pregnancy and their

* Correspondence: Marion.Henderson@glasgow.ac.uk

${ }^{1}$ Medical Research Council/Chief Scientist Office Social and Public Health Sciences Unit, University of Glasgow, Top Floor 200 Renfield Street, Glasgow G2 3AX, Scotland

Full list of author information is available at the end of the article infants who are at higher risk of maltreatment: study protocol for a randomised controlled trial

The original article has been corrected.

\section{Author details}

${ }^{1}$ Medical Research Council/Chief Scientist Office Social and Public Health Sciences Unit, University of Glasgow, Top Floor 200 Renfield Street, Glasgow G2 3AX, Scotland. 'Division of Psychology and Mental Health, School of Health Sciences, The University of Manchester, 2nd Floor Zochonis Building Brunswick Street, Manchester M13 9PL, England. ${ }^{3}$ Health Economics and Health Technology Assessment, University of Glasgow, Glasgow G12 8QQ, Scotland. ${ }^{4}$ Robertson Centre for Biostatistics, Boyd Orr Building, University of Glasgow, Glasgow G12 800. Scotland. ${ }^{5}$ Centre for Rural Health, University of Aberdeen, The Centre for Health Science, Old Perth Road, Inverness IV2 3JH, Scotland. Institute of Health and Wellbeing, University of Glasgow,

Caledonia House, Royal Hospital for Sick Children, Yorkhill, Glasgow G3 8SJ, Scotland. ${ }^{7} \mathrm{NHS}$ Ayrshire and Arran, Afton House, Ailsa Hospital Campus, Dalmellington Road, Ayr KA6 6AB, Scotland. ${ }^{8}$ Institute of Health and Society, School of Education, Communication and Language Sciences, University of Newcastle, Newcastle-upon-Tyne NE1 7RU, England. 9Parenting and Family Support Research Programme, Department of Psychology and Allied Health Sciences, School of Health and Life Sciences, Glasgow Caledonian University, Cowcaddens Road, Glasgow G4 OBA, Scotland.

Published online: 10 September 2019 International License (http://creativecommons.org/licenses/by/4.0/), which permits unrestricted use, distribution, and reproduction in any medium, provided you give appropriate credit to the original author(s) and the source, provide a link to the Creative Commons license, and indicate if changes were made. The Creative Commons Public Domain Dedication waiver (http://creativecommons.org/publicdomain/zero/1.0/) applies to the data made available in this article, unless otherwise stated. 


\section{Reference}

1. Henderson $\mathrm{M}$, et al. Trial of healthy relationship initiatives for the very early years (THRIVE), evaluating Enhanced Triple P for Baby and Mellow Bumps for those with additional social and care needs during

pregnancy and their infants who are at higher risk of maltreatment: study protocol for a randomised controlled trial. Trials. 2019;20:499. https://doi.org/10.1186/s13063-019-3571-5. 